\section{Aonde está o direito ao aborto? Comentário sobre o documentário Zika, The Film}

\author{
Where is the right to abortion? Comment on the \\ documentary Zika, The Film
}

\author{
¿Dónde está el derecho al aborto? Comentario \\ sobre el documental Zika, The Film
}

\author{
${ }^{1}$ Ipas Brasil, Rio de Janeiro, \\ Brasil. \\ Correspondência \\ B. Galli \\ P. O. Box 9990, Chapel Hill, \\ NC 27515, U.S.A. \\ gallib@ipas.org
}

A pergunta está implícita em Zika, The Film, um documentário de 30 minutos (https://www. youtube.com/watch?v=j9tqt0jaoG0), produzido por Debora Diniz, da organização feminista Anis - Instituto de Bioética, com o objetivo de documentar o impacto do vírus Zika para a vida e a saúde das mulheres grávidas de Campina Grande e arredores, no Estado da Paraíba, Brasil. O documentário faz parte da estratégia de advocacy da Anis pelo direito à maternidade segura e pelo direito à saúde integral como parte de direitos sociais constitucionais, que serão demandados em futura uma ação judicial junto ao Supremo Tribunal Federal. A ação aponta para o contexto de epidemia do vírus Zika, declarada como emergência global de saúde pública pela Organização Mundial da Saúde, considerados os efeitos da síndrome congênita associada ao vírus, como a microcefalia e outras más-formações.

O sensível registro etnográfico de Diniz documenta a vivência de cinco mulheres que foram infectadas pelo vírus Zika em momentos distintos da sua gravidez. $\mathrm{O}$ aborto como direito não está presente explicitamente na maioria das narrativas das mulheres. Entretanto, o silêncio sobre o aborto é revelador da falta de informação e de opção das mulheres sobre continuar ou não a gravidez, diante do medo, sofrimento emocional e ansiedade quando recebem o diagnóstico de microcefalia associada ao vírus Zika. As histórias individuais são representativas de um grupo de mulheres que vive à margem dos
Beatriz Galli ${ }^{1}$

padrões de desenvolvimento social sustentável, do acesso ao saneamento básico, dos avanços científicos, da informação e do acesso a serviços básicos de saúde.

O documentário começa a partir do momento de interação das mulheres grávidas com o sistema de saúde, na consulta médica aonde o diagnóstico sobre o desenvolvimento fetal é anunciado, e termina com o primeiro caso estudado pela ciência, a partir da narrativa de Géssica, que decidiu doar partes do corpo de seu filho para pesquisas. As mulheres, consideradas da primeira geração de grávidas infectadas pelo vírus, contam suas histórias, inseridas em seus contextos familiares particulares. Ao expectador é oferecida a imersão nessa realidade, guiado por uma câmera atenta que registra as inúmeras barreiras, as quais as mulheres enfrentam no cotidiano do seu trabalho de cuidado e maternagem.

O silêncio sobre o direito ao aborto é revelador do ambiente institucional de omissão de informação sobre direitos reprodutivos das mulheres. No momento do exame de ultrassom, Amanda e Marina não recebem informação suficiente sobre o contexto nacional e global da epidemia, bem como as opções existentes sobre continuar ou não com a gravidez, além dos riscos de um aborto inseguro. A cena em que Amanda, ao sair do consultório, após receber o diagnóstico, tenta se apoiar no corredor comove pela sua dor e desespero. Amanda está só, tem medo pelo que está por vir, mas não recebe atendimento 
psicológico ou apoio emocional necessário e imediato como deveria. São as mulheres as principais responsáveis pelo cuidado: são elas que vão lidar as dificuldades diárias da maternidade.

Além disso, para todas elas existem barreiras para o acesso a um diagnóstico precoce e completo, havendo necessidade de mais exames complementares. Enquanto esperam, a gravidez avança com riscos ainda desconhecidos pela ciência. No caso de Alessandra, mãe de Samuel, faltou informação adequada sobre os riscos do vírus Zika para o desenvolvimento fetal durante o seu pré-natal, evidenciando as falhas do sistema de saúde para lidar com a epidemia e suas consequências. Na história de Ana Angélica, que tem uma filha com microcefalia e impedimentos neurológicos e que necessita de tratamento fisioterápico, a falta de acesso a transporte é um problema. Ela só pode contar com o empréstimo do carro da prefeitura para poder levar a filha ao serviço de saúde e mesmo assim, ela tem que providenciar o combustível para o trajeto.

As cinco histórias denotam as estratégias de sobrevivência em que se apoiam e que se expressam nas pequenas alegrias e na esperança, como na história Alessandra que sonha que seu filho, Samuel, poderá escolher a profissão. As histórias estão ambientadas no sertão, onde cada dia é um novo dia com um desafio a vencer: encher o tanque de gasolina, conseguir uma consulta médica, ter acesso a remédios e a proteção social do Estado. A vida de cada uma das mulheres é uma batalha particular. A opção acertada pela narrativa das próprias mulheres traduz o olhar feminista da documentarista que registra ao mesmo tempo empoderando aquele grupo de mulheres da Paraíba criando empatia com a audiência.
Em um só caso, o de Marina, é garantido o direito ao aborto, pois a gravidez representa risco de vida. O discurso religioso está presente na narrativa da profissional de saúde e de Marina. Porém, naquele caso a opção é por interromper a gravidez, com apoio da equipe médica, pelos riscos para a vida de Marina devido ao aumento de líquido amniótico. Para os outros casos, não foi dada essa possibilidade. O silêncio sobre o direito ao aborto evidencia uma diferença importante de perspectiva para essas mulheres sem escolha em um contexto de restrição de direitos.

Enquanto o mundo tem pressa para encontrar respostas, debate, questiona, pesquisa o vírus Zika, diante da emergência global de saúde pública, a realidade das mulheres grávidas em Campina Grande é crua. Para as mulheres da Paraíba existem apenas incertezas sobre as circunstâncias em que seus filhos irão se desenvolver e nas quais elas poderão exercer a maternidade. Com o futuro incerto, viver o dia a dia, apenas o presente, é uma estratégia de sobrevivência, resiliência e luta.

Através das histórias, das "não escolhas" ou escolhas restringidas sobre a maternidade de Amanda, Alessandra, Marina, Ana Angélica e Géssica, o documentário questiona, nas suas entrelinhas, as lacunas das políticas de saúde e, por isso, é contundente. Ao mesmo tempo, é inspirador e revela a complexa realidade de desigualdades múltiplas por motivo de classe, condição socioeconômica, raça e local de moradia vividas pelas mulheres, apontando para um quadro de profunda injustiça social e falta de autonomia reprodutiva. 